\title{
Determinants of Modern Paediatric Healthcare Seeking in Rural Côte d'Ivoire
}

\author{
Siaka Koné ${ }^{1,2,3 *}$, Günther Fink ${ }^{2,3}$, Nicole Probst-Hensch ${ }^{2,3}$, Clémence Essé ${ }^{1,4}$, \\ Jürg Utzinger ${ }^{2,3}$, Eliézer K. N'Goran ${ }^{1,5}$, Marcel Tanner ${ }^{2,3}$ and Fabienne N. Jaeger ${ }^{2,3}$ \\ ${ }^{1}$ Centre Suisse de Recherches Scientifiques en Côte d'Ivoire, Abidjan, Côte d'Ivoire, ${ }^{2}$ Swiss Tropical and Public Health Institute, \\ Allschwil, Switzerland, ${ }^{3}$ University of Basel, Basel, Switzerland, ${ }^{4}$ nstitut d'Ethnosociologie, Université Félix Houphouët-Boigny, \\ Abidjan, Côte d'Ivoire, ${ }^{5}$ Unité de Formation et de Recherche Biosciences, Université Félix Houphouët-Boigny, Abidjan, Côte \\ $d^{\prime} /$ voire
}

Objectives: To determine factors that influence healthcare seeking among children with fatal and non-fatal health problems.

Methods: Last disease episodes of surviving children and fatal outcomes of children under 5 years of age were investigated by means of an adapted social autopsy questionnaire administered to main caregivers. Descriptive analysis and logistic models were employed to identify key determinants of modern healthcare use.

Results: Overall, 736 non-fatal and 82 fatal cases were assessed. Modern healthcare was sought for $63.9 \%$ of non-fatal and $76.8 \%$ of fatal cases, respectively. In non-fatal cases, young age, caregiver being a parent, secondary or higher education, living $<5 \mathrm{~km}$ from a health facility, and certain clinical signs (i.e., fever, severe vomiting, inability to drink, convulsion, and inability to play) were positively associated with modern healthcare seeking. In fatal cases, only signs of lower respiratory disease were positively associated with modern healthcare seeking. A lack of awareness regarding clinical danger signs was identified in both groups.

Conclusion: Interventions promoting prompt healthcare seeking and the recognition of danger signs may help improve treatment seeking in rural settings of Côte d'Ivoire and can potentially help further reduce under-five mortality.

Keywords: determinants, child health, modern healthcare, Côte d'Ivoire, health and demographic surveillance system, mortality, Taabo

\section{INTRODUCTION}

Despite considerable progress made over the past two decades, under-five mortality remains high in many low- and middle-income countries (LMICs). Although countries have committed to providing equitable access to quality care for their citizens within the 2030 Agenda for Sustainable Development (2030 Agenda, in short), this objective remains a major challenge [1], particularly in settings characterized by persistent socioeconomic disparities in health and access to healthcare services [2-4]. To reach the ambitious mortality reduction goals set in the 2030 Agenda, improvements at the health system levels will likely have to go beyond basic provision of medical care [5-7]. 
An estimated $50 \%$ of the modifiable determinants of health have been attributed to community specific factors, which often determine an individual's willingness and ability to access healthcare services $[1,6]$. To deepen the understanding of the biomedical and social factors that influence disease progression, particularly in potentially fatal cases, social autopsy using a pathway analysis approach has been introduced in some countries [8-10]. Different from (complementary) verbal autopsies focusing on biomedical causes [11], social autopsies directly aim at determining factors contributing to health outcomes at the household, community, and health systems level. An improved understanding of these factors at different levels might aid prevention of morbidity and mortality, which seems particularly important in the context of infectious diseases (e.g., malaria), where timely provision of quality care is essential for patient survival.

In this study, we draw on rich social autopsy data obtained from the Taabo health and demographic surveillance system (HDSS), located in the south-central part of Côte d'Ivoire to identify key determinants of modern healthcare seeking for paediatric illness.

\section{METHODS}

\section{Ethics Statement}

This study received ethical approval from Côte d'Ivoire (reference no. 172/MESRS/DGRSIT/tm) and Switzerland (reference no. EKBB: 263/13). Written informed consent was obtained from parents or legal guardians. Participants could withdraw from the study anytime without further obligations.

\section{Study Setting}

The study was conducted in the Taabo HDSS. Established in late 2008 with an initial population of 37,792 [12, 13], by the end of 2018, the population in the Taabo HDSS had grown to approximately 48,000. The Taabo HDSS is located in a transition zone between tropical rain forest in the South and the savanna in the North, in a primarily rural area. There are 13 villages, over 100 hamlets, and one small town (i.e., Taabo-Cité). The health system is composed of a small hospital in Taabo-Cité and 10 primary healthcare centres located in the main villages. In the hamlets, no health facilities are available but community health workers (CHWs) provide basic health advice, guidance and services. According to verbal autopsy data collected over 3 years (from 2009 to 2011), $85 \%$ of child deaths were due to infectious diseases, with most deaths attributed to malaria and respiratory tract infections $[13,14]$.

\section{Study Design and Data Collection}

We designed a prospective study with two complementary samples; 1) a sample of fatal episodes; and 2) a sample of non-fatal morbidity episodes. We defined fatal cases as children aged 1-59 months, who died in the Taabo HDSS within a 1-year period from January 2017 to January 2018. Child deaths were identified using a standard key informant system as part of regular demographic data collection rounds within the Taabo HDSS.

Non-fatal cases were randomly selected in the main villages from households inhabited by at least one child under the age of 5 years surveyed between January 2017 and January 2018. Overall, there were 780 household visits. During the visits, all illness episodes (not resulting in death) among children under the age of 5 years in the preceding 30 days were recorded. Whenever multiple episodes of illness occurred within the past 30 days, only information on the most recent illness past episode was collected. Of note, both for fatal and non-fatal cases, the study excluded newborns ( $<29$ days of age), as to explicitly focus on the postnatal period.

\section{Social Autopsy}

Social autopsy consisted of a face-to-face interview with the primary caregivers, usually the mother of the child, 2-8 weeks after the child's death. The questionnaire was inspired by the Child Health Epidemiology Reference Group (CHERG) and the International Network for the continuous Demographic Evaluation for Populations and Their Health (INDEPTH) social autopsy questionnaires [9]. After initial questions on household characteristics, child survival, signs and symptoms observed, and disease recognition, questions explored the healthcare seeking behaviour (i.e., decision-making, choice and source of different home-based treatments, traditional and modern medicine providers, potential access barriers including accessibility, acceptability, availability, affordability, adequacy, and cultural factors). Presenting signs and symptoms were investigated with a special focus on those that 1) give information on the general state of the child; 2) indicate potentially severe disease; and 3) likely warrant consultation of a modern healthcare facility.

The questionnaire used for non-fatal cases was somewhat shorter, but was designed to cover the main aspects of the social autopsy form. The Open Data Kit (ODK) was used to build questionnaires in the national language French. Tablets were used for data collection by trained senior staff. ODK data as well as pictures of signed consent forms were uploaded and stored on a secure server.

\section{Quantitative Variables}

The primary outcome of interest was a binary variable for modern healthcare seeking for a given illness episode. All caregivers who answered "yes" to the question "Have you consulted a provider of modern medicine?" were considered to have used modern medicine. Modern healthcare providers included hospital, public, or private health centres. Explanatory variables included 1) sociodemographic characteristics of the concerned child (i.e., age, sex, twin status, and relationship with the caregiver); 2) household and caregivers' characteristics (socioeconomic status, distance to nearest health facility, educational attainment, age, etc.); and 3) signs and symptoms observed by the caregivers. Socioeconomic status was determined using a household-based asset approach using principal component analysis (PCA) with stratification into wealth quintiles [15]. We relied on household and health centres' geographical coordinates, to estimate the distance from child's place of 
TABLE 1 | Socio-demographic characteristics, stratified by modern healthcare seeking for fatal and non-fatal cases. Social Autopsy Project, Côte d'Ivoire, 2017.

\begin{tabular}{|c|c|c|c|c|c|c|}
\hline & \multicolumn{3}{|c|}{ Non-fatal cases } & \multicolumn{3}{|c|}{ Fatal cases } \\
\hline & N (\%) & $\begin{array}{l}\text { Modern healthcare } \\
\text { seeking }\end{array}$ & $\begin{array}{c}\text { No modern } \\
\text { healthcare seeking }\end{array}$ & N (\%) & $\begin{array}{c}\text { Modern healthcare } \\
\text { seeking }\end{array}$ & $\begin{array}{c}\text { No modern } \\
\text { healthcare seeking }\end{array}$ \\
\hline Full sample & $736(100)$ & $470(63.9)$ & $266(36.1)$ & $82(100)$ & $62(75.6)$ & $20(24.4)$ \\
\hline \multicolumn{7}{|l|}{ Child sex } \\
\hline Male & $412(56.0)$ & $272(66.0)$ & $140(34.0)$ & $43(52.4)$ & $28(65.1)$ & 15 (34.9) \\
\hline Female & $324(44.0)$ & $198(61.1)$ & $126(38.9)$ & 39 (47.6) & $34(87.2)$ & $5(12.8)$ \\
\hline \multicolumn{7}{|l|}{ Child age (months) } \\
\hline $1-11$ & $91(12.4)$ & $65(71.4)$ & $26(28.6)$ & $39(47.6)$ & 27 (69.2) & $12(30.8)$ \\
\hline $12-23$ & $176(23.9)$ & $136(77.3)$ & $40(22.7)$ & $25(30.5)$ & $22(88.0)$ & $3(12.0)$ \\
\hline $24-35$ & $178(24.2)$ & $106(59.6)$ & $72(40.4)$ & $10(12.2)$ & $5(50.0)$ & $5(50.5)$ \\
\hline $35-47$ & $153(20.8)$ & $81(52.9)$ & $72(47.1)$ & 7 (8.5) & 7 (100) & - \\
\hline $48-59$ & $138(18.7)$ & $82(59.4)$ & $56(40.6)$ & $1(1.2)$ & $1(100)$ & - \\
\hline \multicolumn{7}{|l|}{ Child twin status } \\
\hline Twin birth & $17(2.3)$ & $11(64.7)$ & $6(35.3)$ & $3(3.7)$ & 1 (33.3) & $2(66.7)$ \\
\hline Single birth & $719(97.7)$ & $459(63.8)$ & $260(36.2)$ & 79 (96.3) & $61(77.2)$ & $18(22.8)$ \\
\hline \multicolumn{7}{|l|}{ Maternal age (years) } \\
\hline $15-19$ & $96(13.0)$ & $63(65.6)$ & $33(34.4)$ & $9(11.0)$ & 3 (33.3) & $6(66.7)$ \\
\hline 20-34 & $414(56.3)$ & $267(64.5)$ & $147(35.5)$ & $56(68.3)$ & $46(82.1)$ & $10(17.8)$ \\
\hline$\geq 35$ & $226(30.7)$ & $140(62.0)$ & $86(38.0)$ & $17(20.7)$ & $13(76.5)$ & $4(23.5)$ \\
\hline \multicolumn{7}{|c|}{ Average number of live birth* } \\
\hline Number of live birth & 3.7 & 3.6 & 3.9 & 4.2 & 4.3 & 3.9 \\
\hline \multicolumn{7}{|l|}{ Previous child death } \\
\hline Yes & $179(35.7)$ & $100(55.9)$ & $79(44.1)$ & 27 (51.9) & $22(81.5)$ & $5(18.5)$ \\
\hline No & $322(64.3)$ & $211(65.5)$ & $111(34.5)$ & $25(48.1)$ & $21(84.0)$ & $4(16.0)$ \\
\hline$N A$ ** & $235()$. & $159()$. & $76()$. & $30()$. & $22()$. & $8()$. \\
\hline \multicolumn{7}{|c|}{ Child relationship with the caregiver } \\
\hline Biological parents & $403(54.8)$ & $263(65.3)$ & $140(34.7)$ & $42(51.2)$ & $36(85.7)$ & $6(14.3)$ \\
\hline Grandparents & $256(34.8)$ & $165(64.4)$ & $91(35.6)$ & $36(43.9)$ & $22(61.1)$ & $14(38.9)$ \\
\hline Other & $77(10.4)$ & $42(54.6)$ & $35(45.4)$ & $4(4.9)$ & $4(100)$ & - \\
\hline \multicolumn{7}{|l|}{ Main caregiver education } \\
\hline None & $401(54.5)$ & $250(62.3)$ & $151(37.7)$ & $66(80.5)$ & $49(74.2)$ & $17(25.8)$ \\
\hline Primary & $221(30.0)$ & $142(64.2)$ & 79 (35.8) & $5(6.1)$ & $3(60.0)$ & $2(40.0)$ \\
\hline Secondary or higher & $86(11.7)$ & $64(74.4)$ & $22(25.6)$ & $10(12.2)$ & $9(90.0)$ & $1(10.0)$ \\
\hline Coranic & $28(3.8)$ & $14(50.0)$ & $14(50.0)$ & $1(1.2)$ & $1(100)$ & - \\
\hline \multicolumn{7}{|c|}{ Household's socioeconomic status } \\
\hline Most poor & $148(20.1)$ & $89(60.1)$ & 59 (39.9) & $17(20.7)$ & $14(82.3)$ & $3(17.7)$ \\
\hline Less poor & $148(20.1)$ & $90(60.8)$ & $58(39.2)$ & $16(19.5)$ & $10(62.5)$ & $6(37.5)$ \\
\hline Middle & $147(20.0)$ & $97(66.0)$ & $50(34.0)$ & $17(20.7)$ & $10(58.8)$ & 7 (41.2) \\
\hline Rich & $152(20.6)$ & $106(69.7)$ & $46(30.3)$ & $18(22.0)$ & $16(88.9)$ & $2(11.1)$ \\
\hline Most rich & $141(19.2)$ & $88(62.4)$ & $53(37.6)$ & $14(17.1)$ & $12(85.7)$ & $2(14.3)$ \\
\hline \multicolumn{7}{|c|}{ Household distance to nearest health facility $(\mathrm{km})$} \\
\hline$<1$ & $160(21.7)$ & $107(66.9)$ & $53(33.1)$ & $18(21.9)$ & $15(83.3)$ & $3(16.7)$ \\
\hline $1-4.9$ & 469 (63.7) & $308(65.7)$ & $161(34.3)$ & $55(67.1)$ & 38 (69.1) & 17 (30.9) \\
\hline$\geq 5$ & $107(14.5)$ & 55 (51.4) & 52 (48.6) & $9(11.0)$ & 9 (100) & - \\
\hline
\end{tabular}

*If mother is the main caregiver.

${ }^{* *}$ No previous child or mother not main caregiver.

residence to the nearest health facility by means of Statageodist package [16].

\section{Statistical Analysis}

All statistical analyses were performed in Stata version 15.0 (StataCorp; College Station, TX, United States) [17]. Data records from caregivers with complete information on diseaserelated morbidity were considered for analysis. Multivariable standard logistic regression models were estimated to identify associations between modern healthcare seeking and a range of child, household, and community characteristics. Logistic regression results were presented as marginal effects (dy/dx), including 95\% confidence interval (CI). Differences and relationships with a $p$-value below 0.05 were considered statistically significant.

\section{RESULTS}

\section{Study Sample}

Overall, 754 children with recent non-fatal episodes and 104 deaths of children aged 1-59 months were identified through household visits in the Taabo HDSS over a 1-year period. Among the non-fatal cases, 736 had complete data records, and hence, were considered as final study sample (Supplementary Figure S1). 
TABLE 2 | Description of disease symptoms by modern healthcare seeking for fatal and non-fatal cases. Social Autopsy Project, Côte d'Ivoire, 2017.

\begin{tabular}{|c|c|c|c|c|c|c|}
\hline & \multicolumn{3}{|c|}{ Non-fatal cases } & \multicolumn{3}{|c|}{ Fatal cases } \\
\hline & Full sample & $\begin{array}{l}\text { Modern } \\
\text { healthcare } \\
\text { seeking }\end{array}$ & $\begin{array}{c}\text { No modern } \\
\text { healthcare } \\
\text { seeking }\end{array}$ & Full sample & $\begin{array}{l}\text { Modern } \\
\text { healthcare } \\
\text { seeking }\end{array}$ & $\begin{array}{c}\text { No modern } \\
\text { healthcare } \\
\text { seeking }\end{array}$ \\
\hline & $N=736(100 \%)$ & $\mathrm{N}=470(63.9 \%)$ & $\mathrm{N}=266(36.1 \%)$ & $N=82(100 \%)$ & $\mathrm{N}=62(75.6 \%)$ & $N=20(24.4 \%)$ \\
\hline \multicolumn{7}{|l|}{ Fever } \\
\hline Fever & $702(95.4)$ & $459(65.4)$ & $243(34.6)$ & $59(72.0)$ & 49 (83.1) & $10(16.9)$ \\
\hline Diarrhoea & $294(40.0)$ & $200(68.0)$ & $94(32.0)$ & $26(31.7)$ & $23(88.5)$ & $3(11.5)$ \\
\hline Severe diarrhoea ${ }^{\mathrm{a}}$ & $210(28.5)$ & $149(71.0)$ & $61(29.0)$ & $23(28.1)$ & $20(87.0)$ & $3(13.0)$ \\
\hline Other diarrhoea & $87(11.8)$ & $52(59.8)$ & $35(40.2)$ & $4(4.9)$ & $4(100)$ & - \\
\hline Vomiting & $282(38.3)$ & $203(72.0)$ & $79(28.0)$ & $28(34.1)$ & 26 (92.9) & $2(7.1)$ \\
\hline Severe vomiting ${ }^{b}$ & $74(10.1)$ & $62(83.8)$ & $12(16.2)$ & $15(18.3)$ & 14 (93.3) & $1(6.7)$ \\
\hline Other vomiting & $208(28.3)$ & $141(67.8)$ & 67 (32.2) & $13(15.8)$ & $12(92.3)$ & $1(7.7)$ \\
\hline Stiff neck & $7(0.9)$ & $7(100)$ & - & $2(2.4)$ & $2(100)$ & - \\
\hline Reduced or loss of consciousness & $450(61.1)$ & $317(70.4)$ & $133(29.6)$ & $76(92.7)$ & $63(82.9)$ & $13(17.1)$ \\
\hline Urinary change & $408(55.4)$ & $289(70.8)$ & $119(29.2)$ & 7 (8.5) & $6(85.7)$ & $1(14.3)$ \\
\hline Bad smell & 249 (33.8) & $161(64.7)$ & $88(35.3)$ & $4(4.9)$ & $4(100)$ & - \\
\hline Dark urine & 321 (43.6) & $231(72.0)$ & $90(28.0)$ & $4(4.9)$ & $3(75.0)$ & $1(25.0)$ \\
\hline Pollakisuria or/and dysuria & $9(1.2)$ & 8 (88.9) & $1(11.1)$ & - & - & - \\
\hline Less urine & $7(0.9)$ & $6(85.7)$ & $1(14.3)$ & $1(1.2)$ & $1(100)$ & - \\
\hline Blood in urine & $3(0.4)$ & $3(100)$ & - & - & - & - \\
\hline Eyes & $262(35.6)$ & $195(74.4)$ & $67(25.6)$ & $22(26.8)$ & $18(81.8)$ & $4(18.2)$ \\
\hline Very swollen & $5(0.7)$ & $1(20.0)$ & $4(80.0)$ & - & - & - \\
\hline Red or discharging & $7(0.9)$ & $6(85.7)$ & $1(14.3)$ & - & - & - \\
\hline Yellow & $183(24.9)$ & $131(71.6)$ & $52(28.4)$ & $8(9.8)$ & $8(100)$ & - \\
\hline Pallor or cyanoses & $224(30.4)$ & $161(71.9)$ & $63(28.1)$ & $52(63.4)$ & $43(82.7)$ & $9(17.3)$ \\
\hline Jaundice & $15(2.0)$ & $13(86.7)$ & 2 (13.3) & $2(2.4)$ & $2(100)$ & - \\
\hline \multicolumn{7}{|l|}{ General state at disease recognition } \\
\hline Vigilance & $359(48.8)$ & $247(68.8)$ & $112(31.2)$ & 75 (91.5) & $62(82.7)$ & $13(17.3)$ \\
\hline Alert & $336(45.6)$ & $197(58.6)$ & $139(41.4)$ & $6(7.3)$ & $3(50.0)$ & $3(50.0)$ \\
\hline Reduced & 356 (48.4) & $244(68.5)$ & $112(31.5)$ & $75(91.5)$ & $62(82.7)$ & $13(17.3)$ \\
\hline Unconscious & $3(0.4)$ & $3(100)$ & - & - & - & - \\
\hline Doesn't know & $41(5.6)$ & $26(63.4)$ & 15 (36.6) & - & - & - \\
\hline Sudden death & - & - & - & $1(1.2)$ & - & $1(100)$ \\
\hline Activity (play) & 605 (82.2) & $413(68.3)$ & $192(31.7)$ & $74(90.2)$ & $61(82.4)$ & $13(17.6)$ \\
\hline Active & $118(16.0)$ & $45(38.1)$ & $73(61.1)$ & 7 (8.5) & $4(57.1)$ & $3(42.9)$ \\
\hline Reduced activity & $456(62.0)$ & 291 (63.8) & $165(36.2)$ & $40(48.8)$ & $36(90.0)$ & $4(10.0)$ \\
\hline None & $149(20.2)$ & $122(81.9)$ & $27(18.1)$ & $34(41.5)$ & $25(73.5)$ & $9(26.5)$ \\
\hline Doesn't know & $13(1.8)$ & $12(92.3)$ & $1(7.7)$ & - & - & - \\
\hline Sudden death & - & - & - & $1(1.22)$ & - & $1(100)$ \\
\hline Food intake & 532 (72.3) & $359(67.5)$ & $173(32.5)$ & $73(89.0)$ & $62(84.9)$ & $11(15.1)$ \\
\hline Normal food intake & $203(27.6)$ & $110(54.2)$ & $93(45.8)$ & $8(9.8)$ & $3(37.5)$ & $5(62.5)$ \\
\hline Less good & $428(58.2)$ & $283(66.1)$ & 145 (33.9) & $54(65.8)$ & $50(92.6)$ & $4(7.4)$ \\
\hline None & $104(14.1)$ & $76(73.1)$ & $28(26.9)$ & $19(23.2)$ & $12(63.2)$ & $7(36.8)$ \\
\hline Doesn't know & $1(0.1)$ & $1(100)$ & - & - & - & - \\
\hline Sudden death & - & - & - & $1(1.2)$ & - & $1(100)$ \\
\hline
\end{tabular}


TABLE 2 | (Continued) Description of disease symptoms by modern healthcare seeking for fatal and non-fatal cases. Social Autopsy Project, Côte d'Ivoire, 2017.

\begin{tabular}{|c|c|c|c|c|c|c|}
\hline & \multicolumn{3}{|c|}{ Non-fatal cases } & \multicolumn{3}{|c|}{ Fatal cases } \\
\hline & Full sample & $\begin{array}{c}\text { Modern } \\
\text { healthcare } \\
\text { seeking }\end{array}$ & $\begin{array}{l}\text { No modern } \\
\text { healthcare } \\
\text { seeking }\end{array}$ & Full sample & $\begin{array}{c}\text { Modern } \\
\text { healthcare } \\
\text { seeking }\end{array}$ & $\begin{array}{l}\text { No modern } \\
\text { healthcare } \\
\text { seeking }\end{array}$ \\
\hline & $N=736(100 \%)$ & $N=470(63.9 \%)$ & $N=266(36.1 \%)$ & $N=82(100 \%)$ & $N=62(75.6 \%)$ & $N=20(24.4 \%)$ \\
\hline \multicolumn{7}{|c|}{ General state when worst ${ }^{c}$} \\
\hline Vigilance & $447(60.7)$ & $314(70.3)$ & $133(29.7)$ & - & - & - \\
\hline Alert & $272(37.0)$ & $142(52.2)$ & $130(47.8)$ & - & - & - \\
\hline Reduced & $431(58.5)$ & 299 (69.4) & $132(30.6)$ & - & - & - \\
\hline Unconscious & $16(2.2)$ & $15(93.7)$ & $1(6.3)$ & - & - & - \\
\hline Doesn't know & $17(2.3)$ & $14(82.4)$ & $3(17.6)$ & - & - & - \\
\hline Activity (play) & $665(90.3)$ & $447(67.2)$ & $218(32.8)$ & - & - & - \\
\hline Active & $71(9.6)$ & $23(32.4)$ & $48(67.6)$ & - & - & - \\
\hline Reduced activity & $412(56.0)$ & $262(63.6)$ & $150(36.4)$ & - & - & - \\
\hline None & $253(34.4)$ & $185(73.1)$ & $68(26.9)$ & - & - & - \\
\hline Food intake & $619(84.1)$ & $413(66.7)$ & 206 (33.3) & - & - & - \\
\hline Normal food intake & $115(15.6)$ & $56(48.7)$ & 59 (51.3) & - & - & - \\
\hline Less good & $431(58.6)$ & $283(65.7)$ & $148(34.3)$ & - & - & - \\
\hline None & $188(25.5)$ & $130(69.2)$ & $58(30.8)$ & - & - & - \\
\hline Doesn't know & $2(0.3)$ & $1(50.0)$ & $1(50.0)$ & - & - & - \\
\hline
\end{tabular}

aSevere diarrhoea: more than 4-5 liquid stools/day or at least 3x/day for $48 \mathrm{~h}$.

${ }^{b}$ Severe vomiting: frequent vomiting for more than $24 \mathrm{~h}$ or vomiting everything a child tries to drink over a period of several hours.

${ }^{c}$ General state when worst: child general state when the health problem was most severe.

Among the fatal cases, 22 were excluded due to incomplete information, resulting in a final analytical sample of 82 fatal cases (Supplementary Figure S2).

\section{Caregivers, Child Socio-Demographic Characteristics, and Modern Treatment Seeking During Child's Illness}

Table 1 summarizes socio-demographic characteristics of caregivers and children, stratified by whether or not children were seeking modern care, both for fatal and non-fatal cases. Of the 736 children in the non-fatal sample, there were more boys $(\mathrm{n}=412)$ than girls $(\mathrm{n}=324)$. Among the 82 fatal cases, there were 43 boys and 39 girls. On average, children in the fatal cases group were younger (mean age: 14.9 vs. 29.8 months in the nonfatal group). While in the non-fatal cases $12.4 \%$ of children were younger than 1 year, this age group accounted for $47.6 \%$ among fatal cases. More than $85 \%$ of caregivers were 20 years and above.

Among both non-fatal and fatal cases, more than $80 \%$ of children lived in households headed by at least one biological parent or grandparent. In general, the children were taken care of by either parents (fatal cases: $51.2 \%$ vs. non-fatal cases: $54.8 \%$ ) or grandparents (fatal cases: $43.9 \%$ vs. non-fatal cases: $34.8 \%$ ). Grandparents of non-survivors were less likely to have sought care at health services compared to parents or other caregivers (fatal cases grandparents: $61.1 \%$ vs. fatal cases biological parents: $85.7 \%$ or fatal cases other parents: $100 \%$ ). In surviving children, care was less frequently sought for children not being a direct offspring.

When the main caregiver was the biological mother of the child, she was also asked about the number of live births and previous experiences of child loss. On average, mothers of fatal cases had given birth more often (fatal cases: 4.2 vs. non-fatal cases: 3.7 live births) and had experienced a previous loss of a child more frequently than mothers of non-fatal cases (44.3\% vs. $30.1 \%)$. Mothers who had already lost a child were overall less likely to use modern healthcare than those who had not experienced a loss (fatal cases: $81.5 \%$ vs. non-fatal cases: $55.9 \%$ ).

More than half of the main caregivers never attended school (54.5\% in non-fatal cases sample vs. $80.5 \%$ in the fatal case sample). More than $80 \%$ of the children lived in households within $5 \mathrm{~km}$ of modern healthcare services (85.4\% in non-fatal cases vs. $89.0 \%$ in fatal cases).

\section{Description of Disease Symptoms}

Table 2 summarizes children's general health state and signs and symptoms of diseases, as observed by caregivers, stratified by healthcare seeking for fatal and non-fatal cases, respectively. Modern care was sought for $63.9 \%$ and $75.6 \%$ of the children with non-fatal and fatal health problems, respectively. In surviving children, fever was the most commonly recognized symptom concerning nearly all investigated cases (95.4\%). Among fatal cases, the reported fever prevalence was $72.0 \%$. Signs of respiratory disease were reported in nearly $60 \%$ of nonfatal cases, of which approximately $10 \%$ showed signs of lower respiratory tract involvement. Lower respiratory tract involvement concerned fatal cases more frequently than non-fatal cases $(15.8 \% \mathrm{vs}$. $5.6 \%)$. Gastrointestinal symptoms as well as symptoms of dehydration were common in both groups, with extreme thirst, more frequently observed by caregivers in the non-fatal group and severe vomiting and the inability to drink both nearly twice as frequent in the fatal group. Convulsions were five times more common in the fatal group (fatal cases: $23.2 \%$ vs. non-fatal cases: $4.8 \%)$.

Reduced or loss of consciousness were frequently reported both among surviving children $(61.1 \%)$ and in the fatal disease group $(92.7 \%)$. Urinary changes were more commonly observed 
TABLE 3 | Association between socio-demographic factors and modern healthcare seeking. Social Autopsy Project, Côte d'Ivoire, 2017.

\begin{tabular}{|c|c|c|}
\hline & Non-fatal cases & Fatal cases \\
\hline & dy/dx (95\% Cl) & dy/dx $(95 \% \mathrm{Cl})$ \\
\hline \multicolumn{3}{|c|}{ Child sex: Reference: male } \\
\hline Female & $-0.05(-0.12,0.02)$ & $0.06(-0.12,0.25)$ \\
\hline \multicolumn{3}{|c|}{ Child age (months): Reference: 48-59 months } \\
\hline $1-11$ & $0.11^{\star}(-0.02,0.24)$ & $0.07(-0.56,0.70)$ \\
\hline $12-23$ & $0.16^{\star \star \star}(0.06,0.27)$ & $0.13(-0.47,0.73)$ \\
\hline 24-35 & $-0.02(-0.13,0.09)$ & $-0.22(-0.91,0.48)$ \\
\hline $35-47$ & $-0.09(-0.21,0.03)$ & $0.04(-0.66,0.75)$ \\
\hline \multicolumn{3}{|c|}{ Child twin status: Reference: twin } \\
\hline Single & $-0.01(-0.24,0.22)$ & $0.33^{*}(-0.00,0.67)$ \\
\hline \multicolumn{3}{|c|}{ Child relationship with the main caregiver: Reference: biological parent } \\
\hline Grandparent & $0.15^{\star \star}(0.02,0.27)$ & $-0.13(-0.42,0.15)$ \\
\hline Other & $0.01(-0.18,0.20)$ & $0.01(-0.56,0.59)$ \\
\hline \multicolumn{3}{|c|}{ Maternal age (in years): Reference: $\geq 35$ years } \\
\hline $15-19$ & $0.01(-0.10,0.13)$ & $-0.41^{\star \star}(-0.77,-0.06)$ \\
\hline 20-34 & $0.01(-0.07,0.09)$ & $0.12(-0.13,0.36)$ \\
\hline \multicolumn{3}{|c|}{ Main care giver education: Reference: secondary or higher } \\
\hline None & $-0.11^{\star \star}(-0.22,-0.01)$ & $-0.02(-0.28,0.24)$ \\
\hline Primary & $-0.11^{\star}(-0.22,0.00)$ & $-0.20(-0.61,0.22)$ \\
\hline Coranic & $-0.27^{\star \star \star}(-0.47,-0.07)$ & $-0.05(-0.67,0.57)$ \\
\hline \multicolumn{3}{|c|}{ Household's socioeconomic status: Reference: most poor } \\
\hline Poor & $0.00(-0.10,0.11)$ & $0.10(-0.22,0.42)$ \\
\hline Middle & $0.03(-0.08,0.14)$ & $0.08(-0.23,0.38)$ \\
\hline Rich & $0.08(-0.03,0.19)$ & $0.26(-0.08,0.60)$ \\
\hline Most rich & $-0.03(-0.14,0.09)$ & $0.02(-0.30,0.35)$ \\
\hline \multicolumn{3}{|c|}{ Household distance to nearest health facility: Reference $\geq 5$ km } \\
\hline$<1 \mathrm{~km}$ & $0.14^{\star \star}(0.01,0.26)$ & $-0.21(-0.54,0.12)$ \\
\hline $1-4.9 \mathrm{~km}$ & $0.12^{\star \star}(0.02,0.23)$ & $-0.19(-0.45,0.07)$ \\
\hline Observations & 736 & 82 \\
\hline \multicolumn{2}{|c|}{$\begin{array}{l}\text { Coefficients displayed are } d y / d x=\text { marginal effect is a change in the probability that } Y=1 \\
\text { with a specific change in } X \text { with } 95 \% \text { confidence intervals }(C / s) \text { in parentheses; adjusted } \\
\text { models control for household, child, and caregiver's characteristics. }\end{array}$} & $\begin{array}{l}\text { the probability that } Y=1 \\
\text { in parentheses; adjusted } \\
\text { istics. }\end{array}$ \\
\hline
\end{tabular}

in the non-fatal group, and pallor or cyanoses were observed twice as often in the fatal $(63.4 \%)$ than in the non-fatal group (30.4\%). No child died due to an accident.

\section{Factors Associated With Modern Healthcare Seeking}

Table 3 presents results from the fully adjusted model, summarizing the associations between modern healthcare seeking and the characteristics of the child, household, and main caregiver. In non-fatal cases, children aged 1-11 months were $11 \%$-points ( $95 \% \mathrm{CI}:-2 \%$-points to $24 \%$-points; $p$-value $<0.1)$ and children aged $12-23$ months were $16 \%$-points (95\% CI: $6 \%$-points to $27 \%$-points; $p$-value $<0.01$ ) more likely to benefit from modern care than children aged 48-59 months. Caregivers who never attended school and those who attained primary and coranic school levels were $11 \%$-points (95\% CI: $-22 \%$-points to $1 \%$-point; $p$-value $<0.05$ ), and caregivers only attending coranic schools were $27 \%$-points (95\% CI: $-47 \%$-point to $-7 \%$-point; $p$-value $<0.01)$ less likely to utilize modern medicine treatment than more highly educated caregivers. Households living less than $1 \mathrm{~km}$ from the nearest health facility, had a $14 \%$-points (95\% CI: $1 \%$-point to $26 \%$-point; $p$-value $<0.05)$ and those households living $1-4 \mathrm{~km}$ away a $12 \%$-points (95\% CI: $2 \%$-points to $23 \%$ points, $p$-value $<0.05)$ higher propensity to attend a modern healthcare provider than those living at least $5 \mathrm{~km}$ away.

Among fatal cases, caregivers or mothers aged $15-19$ years were $41 \%$-points less likely to seek modern healthcare than women aged 35 and older (95\% CI: $-77 \%$-point to $-6 \%$-point; $p$-value $<0.05)$.

\section{Observed Symptoms Associated With Modern Healthcare Seeking}

Table 4 shows the predicted effects of disease signs and symptoms on modern healthcare seeking from alternative logistic models.

In the adjusted analysis of fatal cases (model 5), only signs of lower respiratory track involvement were positively associated with modern healthcare seeking $(\mathrm{dy} / \mathrm{dx}=0.42$; 95\% CI: 0.14-0.70; $p$-value $<0.05)$. In contrast, dark urine was negatively associated with modern healthcare seeking $(\mathrm{dy} / \mathrm{dx}=-0.60$; $95 \%$ CI: -0.97 to $-0.23 ; p$-value $<0.05)$. No associations between modern healthcare seeking and any other symptoms were observed.

In non-fatal cases, when considering only disease-related symptoms, fever $(\mathrm{dy} / \mathrm{dx}=0.25 ; 95 \%$ CI: $0.09-0.41 ; p$-value $<0.01)$, severe vomiting $(\mathrm{dy} / \mathrm{dx}=0.19 ; 95 \% \mathrm{CI}: 0.06-0.33$; $p$-value $<0.01)$, inability to drink $(\mathrm{dy} / \mathrm{dx}=0.19 ; 95 \% \mathrm{CI}$ : $0.02-0.36$; $p$-value $<0.05)$, convulsions $(\mathrm{dy} / \mathrm{dx}=0.54 ; 95 \% \mathrm{CI}$ : $0.12-0.96 ; p$-value $<0.05)$, dark urine $(\mathrm{dy} / \mathrm{dx}=0.08 ; 95 \% \mathrm{CI}$ : $0.01-0.16 ; p$-value $<0.05)$, and eye infection $(\mathrm{dy} / \mathrm{dx}=0.15 ; 95 \%$ CI: $0.01-0.29 ; p$-value $<0.05$ ) were positively associated with modern healthcare seeking. Bad-smelling urine was negatively associated with treatment seeking $(\mathrm{dy} / \mathrm{dx}=-0.08 ; 95 \% \mathrm{CI}:-0.16$ to $-0.01 ; p$-value $<0.05$ ).

Similar marginal effects and trends in symptoms were observed when the general state of the child's health at the beginning of the disease and during the disease's severity was taken into account. Children who were less able to play than usual at the beginning of the disease episode were associated with an $18 \%$-point (95\% CI: $7 \%$-point to $29 \%$-point; $p$-value $<0.01$ ) increase in modern treatment seeking and those who were not able to play at all a 50\%-point (95\% CI: $34 \%$-point to $66 \%$-point; $p$-value $<0.01)$ increase. Unconsciousness was associated with a $7 \%$-point increased in treatment seeking (95\% CI: $-1 \%$-point to $14 \%$-point; $p$-value $<0.1)$. Similar results were obtained when disease severity symptoms at the point when the disease was most severe were analyzed (model 3 ). In contrast, modern treatment seeking was not taken up when the child ate less than usual or could not eat at all.

With regard to symptoms in fatal cases, fever $(\mathrm{dy} / \mathrm{dx}=0.26$; 95\% CI: $0.06-0.46$; $p$-value $<0.05)$ and lower respiration tract infections (dy/dx $=0.38$; $95 \% \mathrm{CI}$ : $0.12-0.65$; $p$-value $<0.01)$ were positively associated with modern healthcare seeking (model 4). The change of urine color was negatively associated with modern treatment seeking. 
TABLE 4 | Association between disease symptoms and modern healthcare seeking. Social Autopsy Project, Côte d'Ivoire, 2017.

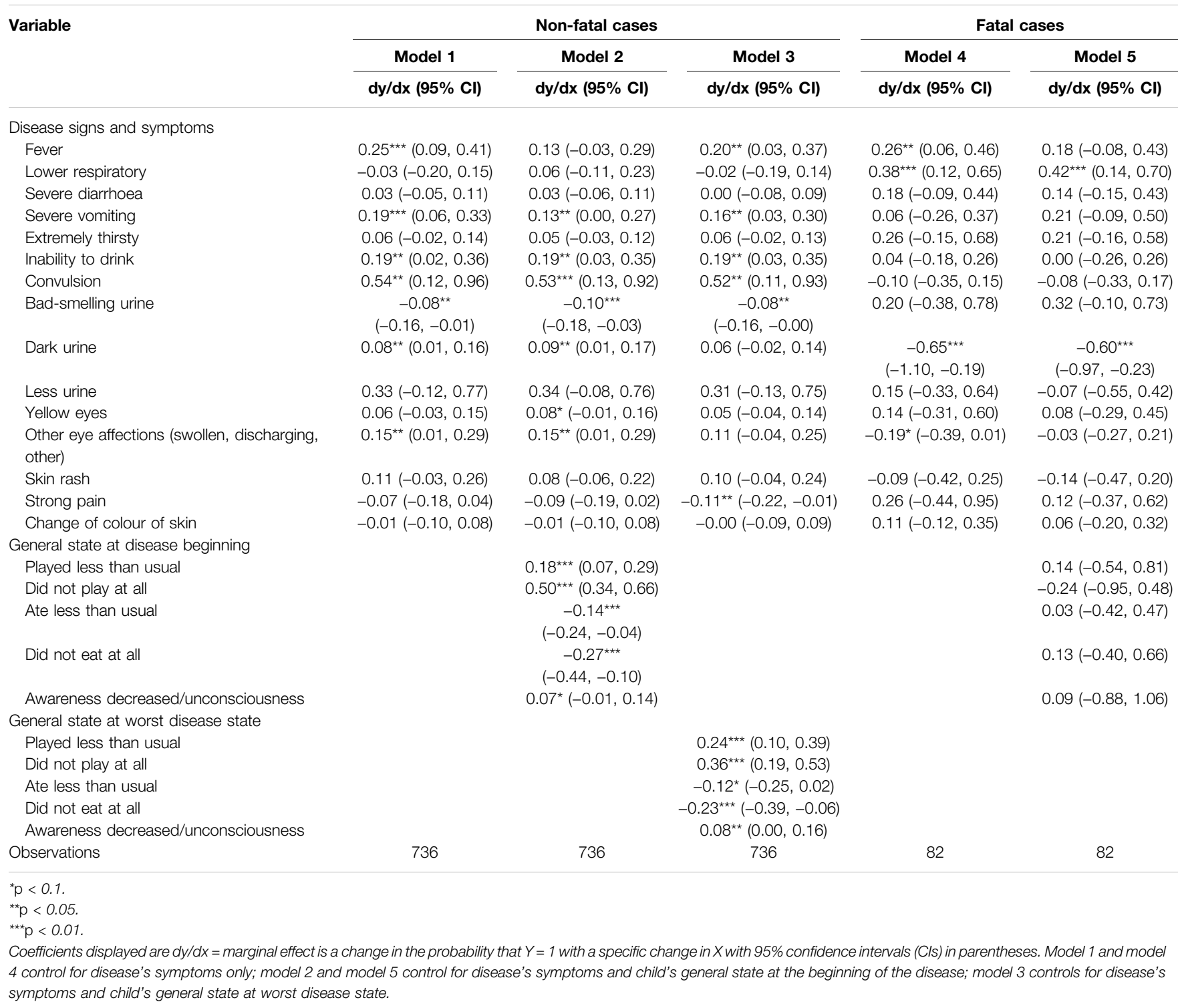

\section{Reasons for Not Seeking Modern Care}

Figure 1 shows the primary reasons caregivers stated for not seeking care. In non-fatal cases, among the 231 respondents, $50.2 \%$ felt that the child was not sick enough, $48.5 \%$ highlighted financial constraints, $15.6 \%$ did not consider consulting useful, while $6.9 \%$ indicated to know what the child was suffering from without consultation. Only $2.2 \%$ of caregivers said that they had used drugs already available at home instead of going to a health facility. Transportation difficulties, the absence of the child's father, and unpleasant previous experience with modern health service were reported by $1.7 \%, 1.3 \%$, and $0.9 \%$, respectively.

In fatal cases, the main reason for not seeking care was that the child was not considered sick enough (50\%). Other reasons were the perception that the disease was not treatable by modern medicine $(25 \%)$ or the fact that the child died so soon after occurrence of symptoms (25\%).

\section{DISCUSSION}

This study identified several determinants of modern healthcare seeking in a primarily rural setting in the south-central part of Côte d'Ivoire. Almost two-third (64\%) of caregivers of children aged 1-59 months experiencing a non-fatal health condition sought care. This percentage is considerably higher than the $45.2 \%$ reported in a national study in 2016 [18]. Our estimates exclusively focus on the use of modern healthcare services. However, in the African context, care-seeking behaviours are complex and often characterized by a combination of modern 
Reasons for not seeking modern care

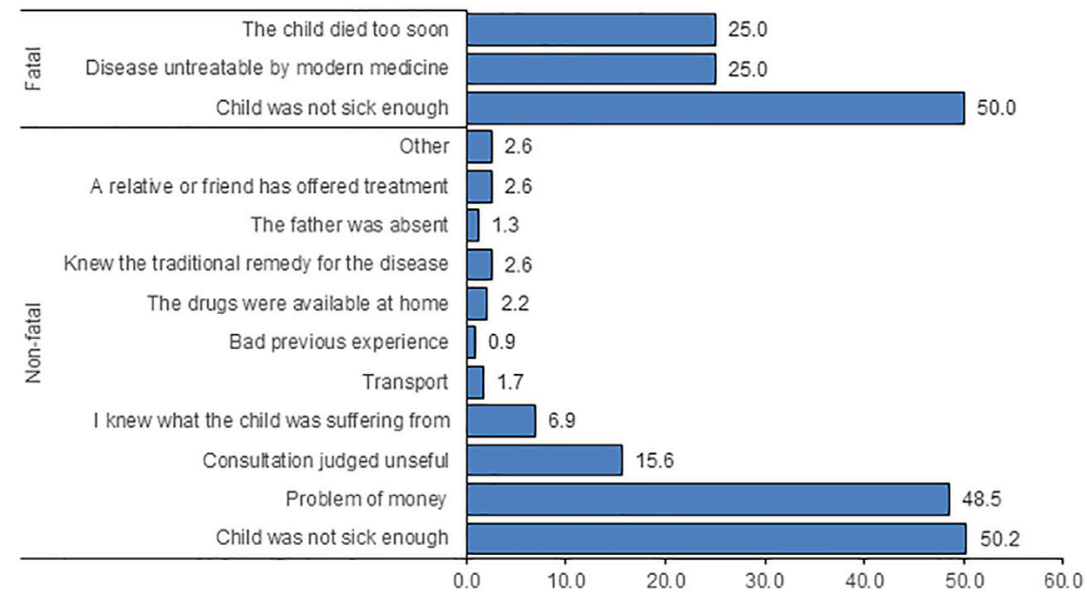

FIGURE 1 | Reasons for not seeking modern healthcare, stratified by cases. Social Autopsy Project, Côte d'Ivoire, 2017.

and traditional medicine [19, 20], and sequential treatment seeking at different systems [21, 22]. Increased treatmentseeking propensity among younger children, among children living with their grandparents, and among caregivers with higher educational attainment appear well aligned with previous research [23-25].

Preceding studies have highlighted geographical distance and socioeconomic status [26-28] as key determinants for health services use. In our study, close proximity to the nearest healthcare facility was associated with increased health seeking for non-fatal cases. Though financial resources were mentioned as a factor for not accessing modern healthcare, we did not find any significant association across socioeconomic groups. This finding is explained by healthcare officially being offered free of charge in Côte d'Ivoire to pregnant women and children under the age of 5 years since 2012 [29]. In Burkina Faso, user fee removal was associated with the use of modern health services across all socioeconomic groups, but this was without adjustment for health needs and distance to health centres [30]. Other studies have shown the effect of wealth on health seeking behaviour, and hence, attributed delays to shortages of financial resources [31, 32]. More than three-quarters of fatal cases sought modern care prior to the death of the child. Caregivers aged $<20$ years were $41 \%$ less likely to bring their child to a modern healthcare provider than those aged $\geq 35$ years, which is in line with previous research $[23,28,33]$. A likely explanation of this observation is that older mothers are more experienced. Compared to those caring for twins, caregivers caring for a single child were more likely to use modern healthcare, suggesting that increased care duties may interfere with timely treatment seeking.

Interestingly, mothers of the fatal cases were more likely to have already experienced the loss of a child. Both in surviving and non-surviving children, mothers with a previous loss were less likely to attend healthcare. Targeted interventions with a nonblaming, empathetic approach focusing on families who have already lost a child, may help increase treatment seeking among high-risk populations and prevent further deaths among young children.

Previous studies indicate the knowledge of danger signs and perceived severity of the illness to be associated with seeking modern healthcare $[34,35]$. In our study, signs and symptoms most strongly associated with healthcare seeking were fever, severe vomiting, inability to drink, convulsion, or dark urine and factors inherent to a child's general state (e.g., child playing less than usual, complete inactivity, decreased vigilance, or unconsciousness). Strikingly, while in surviving children all but one who presented with convulsions were brought in for modern care, the same was true in as many as $20 \%$ among one in five children with fatal disease outcomes, suggesting a lack of recognition of danger signs as a key barrier to timely treatment seeking with severe disease.

While higher rates of signs and symptoms typical for potentially severe disease are expected in fatal cases (e.g., signs of lower respiratory infection), a generally worse state at the time of disease onset may not just be due to more severe disease but also due to late recognition thereof. For non-fatal cases, not seeking external healthcare on the basis that the child was not sick enough, as revealed in the present study, suggests a non-recognition or an underestimation of the signs and symptoms expressed by the child and a lack of knowledge on diseases $[28,36]$. Poor recognition may also hold for fever, the most frequently reported symptom in our study setting, which was only recognized in $72 \%$ of fatal cases, while in nonfatal cases fever was reported in $95 \%$. The high rates of fever and results of the general state variables indicate that many surviving children may have had severe disease, and that pauci-symptomatic illnesses go unnoticed or are not classified as "a child being sick" by caregivers in the Taabo HDSS.

In our study, $36.1 \%$ and $24.4 \%$ of caregivers did not seek modern healthcare in non-fatal and fatal cases, respectively. 
Rather strikingly, in fatal cases, two thirds of the caregivers who did not seek modern healthcare were grandparents and teenage caregivers. Some of the caregivers (with fatal outcomes) appear to have shied away from seeking modern healthcare because they felt a consultation would not be useful, suggesting somewhat limited trust in the local health system. In some cases, a very poor general state (i.e., inactivity, loss of consciousness, and inability to drink) also appears to have resulted in caregivers considering the case lost (too late to seek care). Even though grandparents should have more experience, exposure to modern medicine may be more limited, while past experiences with death may induce beliefs that severe disease courses may be irreversible.

Local norms and beliefs regarding the aetiology of disease [37, 38] appear important. For example, a mother who lost a child in our study reported that the grandparents prevented a child being brought to a modern healthcare facility, as they considered the disease to be treated by prayer alone. In that sense, our results are consistent with several other studies, which have highlighted the importance of the caregivers' skills and educational attainment in child health management [34, 36, 37].

In this study, we used data prospectively collected within a population of more than 45,000 continuously monitored in a well-defined geographical area. This has the advantage of identifying fatalities thoroughly and drawing on a representative sample. While other studies looking at determinants of healthcare seeking have focused on specific pathologies, signs and symptoms, or on fatal cases only, our study provides a more general analysis in both non-fatal and fatal cases of children aged 1-59 months. The fact that the data used relate to the last episode of illness may limit our conclusions as care seeking may vary from one episode to another. In order to gain as representative a picture as possible though, we ensured homogenous data collection over a 1-year period, thus also including seasonal variations. Furthermore, not every caregiver will adhere to the same definition of disease. While the two groups examined cannot be compared directly as the nature of diseases are likely to have been different with numerous illnesses with spontaneous resolution in the surviving group, the focus on signs and symptoms warranting consultation allows for a certain comparison of likelihood of action taken and importance attributed to them. As the responses collected from caregivers relate to the most recent event, a certain recall bias cannot be excluded, though episodes did not lay far back. Social desirability may have played a role though confidentiality was ensured and a very respectful, nonjudgmental attitude was observed to try and minimize this issue.

\section{Conclusion}

The findings presented here from a primarily rural part of Côte d'Ivoire suggest that an increasingly large proportion of caregivers seek modern care for their under 5-year-old children. Nonetheless, a quarter of fatal, and more than a third of non-fatal diseases, were not seen by modern healthcare providers. Increasing the perceived need and urgency of treatment for severe cases as well as improving the overall quality of care are of critical importance if further improvements reducing child mortality are to be achieved in LMICs.

\section{ETHICS STATEMENT}

The studies involving human participants were reviewed and approved by ethical committees in Côte d'Ivoire (reference no. 172/MESRS/DGRSIT/tm) and Switzerland (reference no. EKBB: 263/13). The participants provided their written informed consent to participate in this study.

\section{AUTHOR CONTRIBUTIONS}

Conceived and designed the study: SK and FNJ; performed statistical analyses and summarized the data in tabular and graphical forms: SK and GF; interpreted data and prepared a first manuscript draft: SK, FNJ, and GF; provided important intellectual input to interpretation of findings and manuscript writing: GF, NP-H, JU, CE, EKN, MT, and FNJ; critically reviewed and revised drafts of the paper: JU, NP-H, and GF. All authors read and approved the final manuscript.

\section{FUNDING}

The authors declare that this study was supported by the Centre Suisse de Recherches Scientifiques en Côte d'Ivoire and the Swiss Tropical and Public Health Institute. The funder was not involved in the study design, collection, analysis, interpretation of data, the writing of this article or the decision to submit it for publication.

\section{CONFLICT OF INTEREST}

The authors declare that the research was conducted in the absence of any commercial or financial relationships that could be construed as a potential conflict of interest.

\section{SUPPLEMENTARY MATERIAL}

The Supplementary Material for this article can be found online at: https://www.ssph-journal.org/articles/10.3389/ijph.2021.1604451/ full\#supplementary-material

Supplementary Figure S1 | Flow chart indicating non-fatal cases registered in 2017 in the Taabo health and demographic surveillance system in the south-central part of Côte d'Ivoire. Social Autopsy Project, Côte d'Ivoire, 2017.

Supplementary Figure S2 | Flow chart indicating fatal cases registered in 2017 in the Taabo health and demographicsurveillance system in the south-central part of Côte d'Ivoire. Social Autopsy Project, Côte d'Ivoire, 2017. 


\section{REFERENCES}

1. Oliver A, Mossialos E. Equity of Access to Health Care: Outlining the Foundations for Action. J Epidemiol Community Health (2004) 58(8):655-8. doi:10.1136/ jech.2003.017731

2. Gwatkin DR. The Need for Equity-Oriented Health Sector Reforms. Int J Epidemiol (2001) 30(4):720-3. doi:10.1093/ije/30.4.720

3. Gwatkin DR, Wagstaff A, Yazbeck A Reaching the Poor with Health, Nutrition, and Population Services: What Works, what Doesn't, and Why. Washington, DC: The World Bank (2005). p. 353.

4. Victora CG, Wagstaff A, Schellenberg JA, Gwatkin D, Claeson M, Habicht J-P. Applying an Equity Lens to Child Health and Mortality: More of the Same Is Not Enough. Lancet (2003) 362(9379):233-41. doi:10.1016/s0140-6736(03)13917-7

5. United Nations Inter-Agency Group for Child Mortality Estimation (UN IGME). Levels \& Trends in Child Mortality. New York, NY: UNICEF (2018).

6. Amy BS, Hailey A, Reem A, Becky C, Zach R, Amy RM. A New Approach to Reduce Infant Mortality and Achieve Equity. Ohio: Health Policy Institute (2017).

7. Schoeps A, Gabrysch S, Niamba L, Sié A, Becher H. The Effect of Distance to Health-Care Facilities on Childhood Mortality in Rural Burkina Faso. Am J Epidemiol (2011) 173(5):492-8. doi:10.1093/aje/kwq386

8. Boschi-Pinto C, Young M, Black RE. The Child Health Epidemiology Reference Group Reviews of the Effectiveness of Interventions to Reduce Maternal, Neonatal and Child Mortality. Int J Epidemiol (2010) 39(Suppl. 1): i3-6. doi:10.1093/ije/dyq018

9. Kalter HD, Salgado R, Babille M, Koffi AK, Black RE. Social Autopsy for Maternal and Child Deaths: A Comprehensive Literature Review to Examine the Concept and the Development of the Method. Popul Health Metrics (2011) 9:45. doi:10.1186/1478-7954-9-45

10. Koffi AK, Kalter HD, Kamwe MA, Black RE. Verbal/Social Autopsy Analysis of Causes and Determinants of Under-5 Mortality in Tanzania from 2010 to 2016. J Glob Health (2020) 10(2):020901. doi:10.7189/jogh.10.020901

11. Thomas L-M, D'Ambruoso L, Balabanova D. Verbal Autopsy in Health Policy and Systems: A Literature Review. BMJ Glob Health (2018) 3(2):e000639. doi:10.1136/bmjgh-2017-000639

12. Koné S, Baikoro N, N'Guessan Y, Jaeger FN, Silué KD, Fürst T, et al. Health \& Demographic Surveillance System Profile: The Taabo Health and Demographic Surveillance System, Côte d'Ivoire. Int J Epidemiol (2015) 44(1):87-97. doi:10.1093/ije/dyu221

13. Koné S, Fürst T, Jaeger FN, Esso ELJC, Baïkoro N, Kouadio KA, et al. Causes of Death in the Taabo Health and Demographic Surveillance System, Côte d'Ivoire, from 2009 to 2011. Glob Health Action (2015) 8:27271. doi:10.3402/gha.v8.27271

14. Streatfield PK, Khan WA, Bhuiya A, Hanifi SMA, Alam N, Ouattara M, et al. Cause-specific Childhood Mortality in Africa and Asia: Evidence from INDEPTH Health and Demographic Surveillance System Sites. Glob Health Action (2014) 7:25363. doi:10.3402/gha.v7.25363

15. Filmer D, Pritchett LH. Estimating Wealth Effects without Expenditure DataOr Tears: An Application to Educational Enrollments in States of India. Demography (2001) 38(1):115-32. doi:10.2307/3088292

16. Picard R. GEODIST: Stata Module to Compute Geographical Distances. Statistical Software Component. Revised 24 Jun 2019. Boston College: Department of Economics (2010).

17. StataCorp. Stata Statistical Software: Release. College Station. TX: StataCorp (2017).

18. Institut National de la Statistique (INS) Fonds des Nations Unies pour l'Enfance (UNICEF). Côte d'Ivoire - Enquête par Grappes à Indicateurs Multiples (MICS) 2016Ref. CIV_2016_MICS_v01_M. 16 June 2021.

19. Sy I, Keita M, Taleb M, Lo B, Tanner M, Cissé G. Recours aux Soins et Utilisation des Services de Santé à Nouakchott (Mauritanie): Inégalités Spatiales ou Pesanteurs Sociales? (2010).

20. Ishaga C, Keita B, Kuepi M. Determining Factors of the Therapeutic Resort in Mali: Between Sociocultural, Economical and Geographical Accessibility Factors. Popul Développement en Afrique (2010) 2:147-76. [in French].

21. Pilkington H, Mayombo J, Aubouy N, Deloron P. Malaria, from Natural to Supernatural: A Qualitative Study of Mothers' Reactions to Fever (Dienga, Gabon). J Epidemiol Community Health (2004) 58(10):826-30. doi:10.1136/ jech.2003.016089
22. Médah R. Sociological Approach of Health Care Offer and Demand, the Example of Injections in the City of Ouagadougou (Burkina Faso). Etude Recit No 11. Ouagadougou: Laboratoire Citoyennetés (2006). p. 22.

23. Dagnew AB, Tewabe T, Murugan R. Level of Modern Health Care Seeking Behaviors Among Mothers Having under Five Children in Dangila Town, North West Ethiopia, 2016: A Cross Sectional Study. Ital J Pediatr (2018) 44(1):61. doi:10.1186/s13052-018-0503-Z

24. Pierce H, Gibby AL, Forste R. Caregiver Decision-Making: Household Response to Child Illness in Sub-Saharan Africa. Popul Res Pol Rev (2016) 35(5):581-97. doi:10.1007/s11113-016-9396-y

25. Vikram K, Vanneman R, Desai S. Linkages between Maternal Education and Childhood Immunization in India. Soc Sci Med (2012) 75(2):331-9. doi:10.1016/j.socscimed.2012.02.043

26. Begashaw B, Tessema F, Gesesew HA. Health Care Seeking Behavior in Southwest Ethiopia. PLoS One (2016) 11(9):e0161014. doi:10.1371/journal.pone.0161014

27. Borah H, Gogoi G, Saikia H. Health Seeking Behaviour of the Mothers for Illness of Their Under Five Children in Slums of Dibrugarh Town, Assam, India. Int J Community Med Public Health (2016) 3:145-8. doi:10.18203/23946040.ijcmph20151550

28. Weldesamuel GT, Alemayoh TT, Atalay HT, Zemichael TM. Modern HealthSeeking Behaviour and Associated Factors Among Mothers Having Under 5Years Old Children in Shire Town, Tigray, Ethiopia: A Cross-Sectional Study 2018. Afr J Prim Health Care Fam Med (2019) 11(1):e1-e6. doi:10.4102/ phcfm.v1li1.1913

29. Ministère de la Santé et de la Lutte Contre le Sida. Plan National de Développement Sanitaire 2012-2015. Côte d'Ivoire, avril (2012).

30. Ridde V, Haddad S, Heinmüller R. Improving Equity by Removing Healthcare Fees for Children in Burkina Faso. J Epidemiol Community Health (2013) 67(9):751-7. doi:10.1136/jech-2012-202080

31. Kassile T, Lokina R, Mujinja P, Mmbando BP. Determinants of Delay in Care Seeking among Children Under Five With Fever in Dodoma Region, Central Tanzania: A Cross-Sectional Study. Malar J (2014) 13(1):348. doi:10.1186/14752875-13-348

32. Scott K, McMahon S, Yumkella F, Diaz T, George A. Navigating Multiple Options and Social Relationships in Plural Health Systems: A Qualitative Study Exploring Healthcare Seeking for Sick Children in Sierra Leone. Health Policy Plan (2014) 29(3):292-301. doi:10.1093/heapol/czt016

33. Gelaw YA, Biks GA, Alene KA. Effect of Residence on Mothers' Health Care Seeking Behavior for Common Childhood Illness in Northwest Ethiopia: A Community Based Comparative Cross-Sectional Study. BMC Res Notes (2014) 7(1):705. doi:10.1186/1756-0500-7-705

34. Kolola T, Gezahegn T, Addisie M. Health Care Seeking Behavior for Common Childhood Illnesses in Jeldu District, Oromia Regional State, Ethiopia. PLoS One (2016) 11(10):e0164534. doi:10.1371/journal.pone.0164534

35. Wambui WM, Kimani S, Odhiambo E. Determinants of Health Seeking Behavior Among Caregivers of Infants Admitted with Acute Childhood Illnesses at Kenyatta National Hospital, Nairobi, Kenya. Int J Pediatr (2018) 2018:5190287. doi:10.1155/2018/5190287

36. Geldsetzer P, Williams TC, Kirolos A, Mitchell S, Ratcliffe LA, Kohli-Lynch MK, et al. The Recognition of and Care Seeking Behaviour for Childhood Illness in Developing Countries: A Systematic Review. PLoS One (2014) 9(4): e93427. doi:10.1371/journal.pone.0093427

37. Dougherty L, Gilroy K, Olayemi A, Ogesanmola O, Ogaga F, Nweze C, et al. Understanding Factors Influencing Care Seeking for Sick Children in Ebonyi and Kogi States, Nigeria. BMC Public Health (2020) 20(1):746. doi:10.1186/s12889-02008536-5

38. Kouadio MBK, Righetti AA, Abé NN, Wegmüller R, Weiss MG, N'Goran EK, et al. Local Concepts of Anemia-Related Illnesses and Public Health Implications in the Taabo Health Demographic Surveillance System, Côte d'Ivoire. BMC Hematol (2013) 13(1):5. doi:10.1186/2052-1839-13-5

Copyright (c) 2022 Koné, Fink, Probst-Hensch, Essé, Utzinger, N'Goran, Tanner and Jaeger. This is an open-access article distributed under the terms of the Creative Commons Attribution License (CC BY). The use, distribution or reproduction in other forums is permitted, provided the original author(s) and the copyright owner(s) are credited and that the original publication in this journal is cited, in accordance with accepted academic practice. No use, distribution or reproduction is permitted which does not comply with these terms. 